\title{
REGIONAL ECONOMIC FLUCTUATIONS: PORTFOLIO VARIANCE AND INDUSTRIAL INSTABILITY ACROSS METRO AREAS
}

\author{
James A. Kurre and Clifford H. Woodruff III*
}

\begin{abstract}
Portfolio variance analysis is a useful tool for examining both a region's industrial diversification and its cyclical instability. Ideally, it can guide policy makers in choosing industrial targets that will reduce regional instability. However, for portfolio variance to be a useful tool, policy makers must be able to predict the effect of a new industry on the local economy. This paper applies portfolio variance analysis to 17 American MSAs in order to determine the cyclical characteristics of industries and to determine if they are consistent across regions. We also examine regional business cycle amplitude and how it relates to a region's industrial structure. In the process, we identify a technique for measuring the contribution of each industry to an MSA's instability and for separating that effect into portions due to the size of the industry and its cyclical behavior.
\end{abstract}

\section{INTRODUCTION}

It is hardly revolutionary to suggest that some metro areas feel the effects of a recession much more than others. Reporters doing stories about national recessions frequently pay a visit to a traditional factory town, since the durable manufacturing industries that provide the economic base of such towns are always hard hit when the crunch comes. This suggests immediately that regional recession impact varies with industrial structure; presumably those areas that specialize in goods and services that face income-elastic demands will feel both the ups and the downs of the cycle more than other areas.

But analyzing a region's fluctuations by focusing on its industrial structure can be misleading, because a region's cycle is more than just the sum of the cycles of its individual industries. In a sense, the whole is more than the sum of the parts. To get the full picture we have to look at both the timing of the cycles and the reinforcing or offsetting interactions of the industries locally. This can be done through the framework of portfolio variance analysis, which conveniently breaks a region's fluctuations into portions due to the cycles of individual industries, and portions due to the interactions of those industries. With a little im-

\footnotetext{
*Associate Professor of Economics, Pennsylvania State University at Erie, the Behrend College, and Regional Economist, Bureau of Economic Analysis, U.S. Department of Commerce, respectively. This research was funded in part by a grant from the Manufacturers' Association of Northwest Pennsylvania. Views expressed in this paper do not necessarily reflect the opinions of the Bureau of Economic Analysis, the U.S. Department of Commerce, or the Manufacturers' Association of Northwest Pennsylvania. We would also like to express our gratitude to the anonymous referees for their suggestions.
} 
agination, we can even apportion the region's total variability to its activities on an industry-by-industry basis, being careful to take account of interaction effects.

The question this paper seeks to answer is whether the effects of a given industry are the same across metro areas. If industry $\mathrm{X}$ is very pro-cyclical in the nation as a whole, will it necessarily be pro-cyclical in metro area A? More to the point, if industry $\mathrm{Y}$ is generally known to be relatively stable over the cycle, or even countercyclical, will a policy of attracting firms in this industry to the area necessarily result in a more stable local economy? To what extent is the cyclical behavior of an industry consistent across metro areas?

This paper will address those questions through an examination of the cyclical behavior of ten industries that account for all nonagricultural employment in 17 U.S. metropolitan statistical areas (MSAs) over a complete business cycle. We will compare the reaction of each industry in each MSA to that of the industry nationally and identify the degree to which each industry contributes to each MSA's fluctuations in employment. Finally, we will assess the consistency of each industry's cyclical behavior across MSAs.

The paper begins with an overview of portfolio variance concepts and techniques, followed by an explanation of the data used in this study. The fourth part of the paper presents the empirical results, measuring overall instability of each MSA, then decomposing the instability into portions attributable to individual industry cycles and inter-industry effects. This allows an examination of the consistency of industries' patterns across areas. The final section summarizes the findings.

\section{OVERVIEW OF THE PORTFOLIO VARIANCE TECHNIQUE}

\section{A. Basics}

It was Conroy $(1972,1975)$ who suggested that portfolio variance analysis from financial theory could be applied in the realm of regional economics. According to his formulation, the region is analogous to an investor whose portfolio of assets is the set of industries that make up the local economy. Each industry yields a return to the region in the form of employment. Each also entails a risk in the form of fluctuations in return from its expected value. The risk is measured, as in financial theory, by the variance of the asset's return. The risk of the entire portfolio is the portfolio variance, and can be represented as:

$$
\sigma_{P}^{2}=\sum_{i} \sum_{j} w_{i} w_{j} \sigma_{i j}
$$


where $\mathrm{w}_{\mathrm{i}}$ is industry i's weight in the region's portfolio (i.e., i's percentage of total local employment), and $\sigma_{i j}$ is the covariance between industry i's and industry j's returns. A larger portfolio variance indicates greater instability in the local economy.

By separating out the cases in which $i$ equals $j$, the portfolio variance equation can be rewritten as:

$$
\sigma_{P}^{2}=\sum_{i} w_{i}^{2} \sigma_{i}^{2}+\sum_{i \neq j} \leftarrow \sum_{j \neq i} w_{i} w_{j} \sigma_{i j}
$$

The first of the right-hand terms is the weighted sum of the variances for all industries, while the second term is the weighted sum of the covariances between all pairs of industries. This form of the equation is especially useful for drawing attention to the fact that it is important to look both at the internal variability of each industry (the variances), and also at how each industry's pattern of fluctuations reinforces or offsets those of other industries (the covariances). A positive covariance indicates that two industries tend to fluctuate together over time, leading to greater instability in the local economy. A negative covariance indicates that one industry tends to be on the upturn while the other is on the downturn, leading to a more stable economy.

Before calculating the variance and covariance elements for an MSA, it is necessary to recognize that different areas-and even different industries within an area-can have quite different long-run trends in employment. The purpose of portfolio variance analysis is to analyze fluctuations around trend, so calculation of the variance and covariance values is done using detrended employment data. In other words, deviations from trend are used in this process rather than the actual employment data. If this were not done, differences in trend between two industries would be counted by the analysis as another form of instability. This is clearly not the intent of the analysis. We follow Conroy's lead in using the relative deviations of the data from quadratic trends.

Portfolio variance and the related issues of industrial structure and regional instability have been widely discussed in the literature recently. (See, for example, Schoening and Sweeney (1989, 1992), Board and Sutcliffe (1991), Coulson (1993), and Malizia and Ke (1993).) Rather than presenting a necessarily limited literature review here, we will direct interested readers to Kort's (1991) excellent overview of the topic, including its historical antecedents, development, and policy uses. 


\section{B. Methodological Issues}

Before calculating the portfolio variance for a region, we must address several methodological issues, including the time period of analysis, the method of calculating industry weights, the method of calculating the interindustry covariances, and the use of raw versus smoothed data. See Kurre and Weller (1989) and Kurre and Woodruff (1990b) for a more detailed treatment of these topics.

\section{Period of analysis}

In order to present an accurate portrait of local patterns of industry fluctuations, it is necessary to look at time periods in terms of full business cycles, based on local turning points. Portfolio variance analysis examines the covariances between pairs of industries' employment or income patterns. If a period of time other than full business cycles is used to measure that relationship, an incorrect conclusion may be drawn about the relationship of the two industries.

For example, consider a situation in which two industries are only slightly out of phase with each other in terms of their cyclical timing. During most of the cycle these two industries move in the same direction, but one of the industries leads the other at cyclical turning points by, say, four months. If the period chosen for portfolio variance analysis happens to be just the four months after a turning point, the covariance between the two industries will appear to be negative, despite the fact that their relationship over the whole cycle would show a positive covariance. Likewise, using some period for analysis that excludes this fourmonth period or includes a post-trough period on each end of the cycle would yield a false measure of the covariance; the inverse portion of the relationship would be omitted or counted twice. For this reason, it is necessary to specify that the period of analysis must begin and end at the same point of the cycle. The easiest way to do this is to use peak-to-peak or trough-to-trough periods.

A related issue concerns the fact that regional peaks and troughs do not necessarily coincide with national turning points. (See Kurre, Weller and Woodruff (1991).) Imposing national turning points on all MSAs in the sample could result in the problems mentioned above, so it is necessary to use local turning points in portfolio variance analysis.

\section{Industry weights}

In calculating the region's portfolio variance, the individual industry variances and covariances are weighted by the importance of the industry in the local 
economy. The importance of an industry (the w's in equations 1 and 2) is typically measured as its percentage of total employment, but this percentage can vary due to both seasonal and cyclical forces. As a result, it is necessary to specify a method for calculating these weights.

Researchers have used different methods in the past. Conroy (1975) used a one-year period near the middle of his period of analysis, reasoning that a oneyear period would avoid seasonal effects. Jackson (1984) used weights from the beginning of the period under study, since his focus was on picking industries to stabilize future cycles. Both of these methods are subject to cyclical influences on the industrial structure, however. An alternative method would be to use the average weight for the whole period to avoid both seasonal and cyclical effects.

An experiment by Weller and Kurre (1985) to test the sensitivity of portfolio variance analysis to the weighting technique found that the overall portfolio variance was not much affected by the technique used. The individual industry variances were affected in a significant way by the weighting method, however, so choice of weighting method is not a moot point. This paper will use the wholeperiod average method for weighting the individual industry variances and covariances, since that method gives the most accurate representation of an industry's importance over the whole cycle.

\section{Regional versus national covariance patterns}

In his original work, Conroy calculated portfolio variance for 52 American SMSAs over a ten-year period. In order to do this, he applied industrial weights from each region to the covariance patterns from the national data. This technique involves the implicit assumption that the interindustry covariance patterns are identical in all metro areas. This need not be true, of course. For example, the cyclical patterns of one region's logging industry that sells to furniture makers could be quite different from another region's logging industry that sells to paper makers. Likewise, one region's plastics industry might exhibit considerable cyclical instability, since its primary customer is a single automobile manufacturer, compared to another region's plastics industry, which sells to a varied set of producers of nondurable goods.

Work done by Kurre and Weller (1984) indicated that the portfolio variance measure was quite sensitive to the variance-covariance matrix used. Use of the local matrix resulted in portfolio variances as much as 72 percent higher than with the corresponding national matrix. Brown and Pheasant (1985) and Schoening and Sweeney (1989) found similar results. Since it is the local variancecovariance matrix that actually measures the patterns of local industries, it is the one that will be used in this paper. 


\section{Raw versus smoothed or seasonally adjusted data}

It has been suggested that portfolio variance studies should use smoothed or seasonally adjusted data rather than raw data. This can be tied to other suggestions that regional officials should be concerned only with unanticipated or nonsystematic fluctuations in employment or income and not worry about predictable changes. Presumably, cyclical patterns that are anticipated can be planned for and thus do not present a serious problem. An analogy might be that jobs that offer more uncertain employment-say only seasonal work-have to pay a premium-a compensating differential-to offset this negative aspect of the job. Some argue that, as a result, fluctuations that can be predicted should not be a part of our concern. $^{1}$

On the other hand, an economy that experiences fluctuations in employment levels is less efficient than one that produces the same amount of output with steady levels of employment. The unstable economy would have to produce at a fast rate during its "up" periods in order to offset idle workers and plants during its "down" times. This implies larger plants to produce the same amount of output over a cycle, and therefore higher capital costs. Also, to the extent that seasonal and cyclical fluctuations require more planning and forecasting, they also impose an opportunity cost in terms of the resources that could be used for other purposes. Our conclusion is that an economy that does not fluctuate from its long-run trend would be most efficient. Thus, we use all fluctuations from trend in calculating covariances-both seasonal and cyclical as well as irregular. In other words, the raw, unsmoothed, not seasonally adjusted data are used for this study. We acknowledge, however, that the results of this study might well be quite different if done with seasonally adjusted data, but we believe it more appropriate to include seasonal fluctuations in the analysis as well as cyclical.

\section{DATA}

Like most portfolio variance studies, this one makes use of employment data to measure economic performance. This is partially due to the greater availability of employment data, especially at the monthly level. However, there is empirical evidence (Kurre and Weller, 1989) that firms respond to changes in demand through employment adjustments rather than changes in nominal wages and that changes in weekly hours worked tend to move in harmony with employment changes rather than to offset them. These findings mean that use of employment data is appropriate in studies of instability. This theory was reinforced by later work (Kurre and Woodruff, 1990a) which found that income fluctuations likewise 
tended to be correlated with employment changes, although the income fluctuations were more severe in the case studied.

\section{A. The BLS790 Program}

The employment data used in this study are from the U.S. Bureau of Labor Statistics' Current Employment Statistics survey, also known as the Establishment Survey program, or the BLS790 program. Historical data from this program were published at the monthly level for American states and metro areas in March of 1989 in the five-volume set Employment, Hours and Earnings, States and Areas, 1972-87. Comparable national data are published in Employment, Hours and Earnings, United States, 1909-90. Data for earlier and later periods are available in computer-readable form directly from the BLS.

The BLS790 employment numbers are estimates based on a monthly sample of employers who participate voluntarily in this joint state-federal program. In 1990, the sample included over 340,000 establishments employing over 40 million workers nationwide (BLS, 1991, p. iii). Selection of establishments for inclusion in the sample includes all large employers and a representative group of smaller establishments. The BLS specifies the "concepts, definitions and technical procedures" used by the respective state employment security agencies to prepare the monthly estimates, in order to ensure comparability across states (BLS, 1989, p. iii).

These data reflect a count of jobs, not people. Specifically, the employment numbers include anyone who "received pay for any part of the pay period which includes the 12th day of the month" (BLS, 1989, p. A1). This includes those who are on paid sick leave, holiday or vacation, but excludes agricultural workers, proprietors, the self-employed, unpaid volunteers and family workers, and domestic workers. Strikers are not included if they were on strike during the whole pay period that includes the 12th of the month. A worker with more than one job will be counted more than once in this program.

Although the data are based on sample surveys rather than universe data, they are adjusted each year to benchmarks that are comprehensive employment counts. Each March, data is gathered for all establishments, primarily from unemployment insurance reports from the state employment security agencies (the ES202 data), and the relationships among industries in these data are used to adjust estimates for the previous year. This "benchmarking" procedure takes some time; benchmarked data are typically released in the summer two years after the year under consideration. For example, data for April of 1992 through March of 1993 will be benchmarked to March of 1993, and these data will be released during the summer of 1994. 
Employment data from the BLS790 program are different from those reported in the Employment and Wages (ES202) program of the BLS. BLS790 includes employees such as "those working for interstate railroads or members of religious orders working in parochial schools and churches" who are typically not covered by the unemployment insurance programs and thus are omitted from ES202 (BLS, 1989, p. A4.) These data are gathered from other relevant sources. On the other hand, ES202 includes coverage of some industries (SICs 01-06, 08, 09) omitted from 790. [See the BLS Handbook of Methods, (1988) Chapters 2 and 5 , for more information on these two programs, and White et al. (1990) for a discussion of the ES202 program.]

\section{B. Industry Categories}

Since the goal of portfolio variance analysis is to examine the relationships among industries with respect to their cyclical fluctuations, it is necessary to disaggregate total employment into its industrial components. The greater the industrial detail, the richer the picture painted by portfolio variance analysis. Studies of this type rely on employment series that are consistent over a long period of time with respect to industrial definitions. For this study, data constraints limited us to the following ten industrial categories, which include all nonagricultural employment. (This list also gives the three-letter abbreviations that are used subsequently.) This high level of industrial aggregation is one of the chief drawbacks of this study.

Industry Categories

CON Construction

DUR Durables Manufacturing

NDU Nondurables Manufacturing

TPU Transportation and Public Utilities

WHO Wholesale Trade
RET Retail Trade

FIR Finance, Insurance and Real Estate SVC Services

STL State and Local Government

FED Federal Government (civilian only)

One problem that arises in this connection concerns the treatment of mining employment. In many metro areas, mining was traditionally included in the services category for data collection in the BLS790 program. This was logical for areas like Erie, where mining primarily takes the form of gas well drilling, which could be considered a service. In some MSAs the mining category was later removed from the services category, and data were published for it as a separate industry. In recent years, the mining data have been re-aggregated for some 
MSAs, but with the construction industry rather than with services. And there's the rub.

In order to provide maximum consistency for this study, mining has been aggregated with the services industry wherever possible. This yields consistent data for 11 of the 17 MSAs in this study. In six MSAs, it was impossible to segregate mining from the construction industry for later years and from services for earlier years, so there is an inconsistency in the industry definitions. ${ }^{2}$ In these cases, mining switches from the services to the construction industry starting with 1988, resulting in a drop in the services series and an increase in the construction series in that year.

While less than ideal, this situation should not cause overwhelming problems for this study. The mining category is typically quite small in these MSAs; for example, mining accounts for 100 to 300 jobs in the Erie economy, where total employment is over 100,000 . Also, the cycle that is the focus of this study spans the period from 1975 to 1982 , while the mining problem doesn't intrude until 1988. The only effect this problem may have on the current study is through possible impact on the trend series, which were fitted from 1972 through mid-1991.

\section{Cyclical Endpoints and MSAs Used}

As explained above, portfolio variance analysis must use cyclical turning points as the endpoints of its study period. Cyclical turning points in total employment were identified for a set of MSAs in work done by Kurre, Weller and Woodruff (1991). Recognizing that not all MSAs participate in each cyclical turn, we chose to use the trough-to-trough cycle corresponding to the official National Bureau of Economic Research (NBER) turning points of March 1975 and November 1982. ${ }^{3}$ Total employment for the nation turned up in April 1975 and December 1982, respectively, lagging the overall economy (i.e., the official turning points) by one month in each case. Figure 1 shows the U.S. total employment series, not seasonally adjusted, and the relevant troughs for this analysis.

Of the 26 MSAs for which we had access to disaggregated industrial data, 17 participated in both of these turns. These 17 cover a broad range of types, including small and large, fast and slow-growing, and denizens of the Rustbelt and the Sunbelt. They include counties in 15 states. The sample MSAs are listed below, along with their three-letter abbreviations, which will be used in tables later in the paper. (Shortened versions of the official MSA names are also used in some cases.) Perhaps it should also be mentioned that we used Primary Metropolitan Statistical Areas (PMSAs) rather than Consolidated Metropolitan Statistical Areas (CMSAs) when that distinction was relevant. 
FIGURE 1

U.S. Total Employment

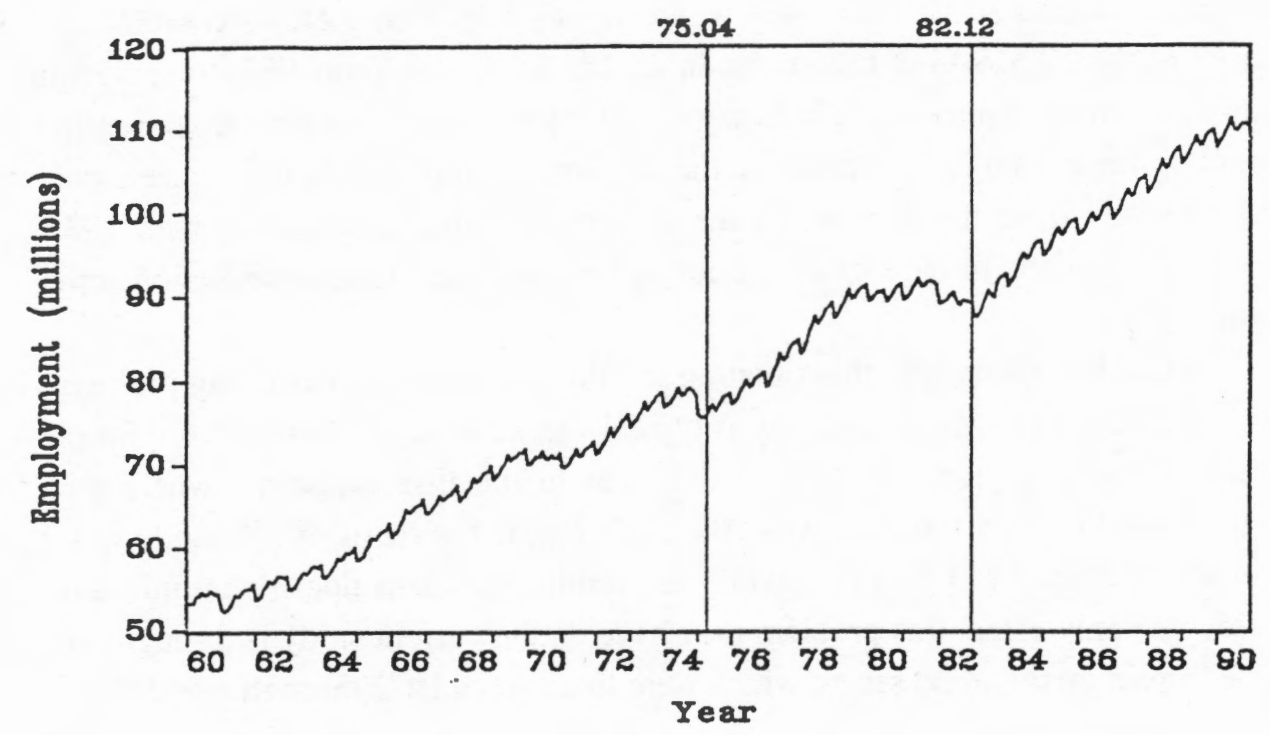

MSAs Included in the Study

ALL Allentown-Bethlehem PA-NJ GRE Greenville-Spartanburg SC

ANN Ann Arbor MI

LAN Los Angeles-Long Beach CA

CIN Cincinnati OH-KY-IN

MEM Memphis TN-AR-MS

CLE Cleveland $\mathrm{OH}$

MIA Miami-Hialeah FL

COM Columbia SC

NAS Nashville TN

COL Columbus GA-AL

OAK Oakland CA

$\mathrm{COB}$ Columbus $\mathrm{OH}$

PIT Pittsburgh PA

ERI Erie PA

RIV Riverside-San Bernardino CA

EUG Eugene-Springfield OR

While all of these MSAs participated in the March 1975 and November 1982 turning points and all had a peak between those two points, four of the MSAs (Allentown, Columbus GA, Memphis, and Nashville) also experienced another trough and its corresponding peak during this period. In fact, the official NBER national turning points include a peak in January 1980, a trough in July 1980, and another peak in July 1981 . This represents a very short cycle, however, and even the national employment series did not register this mini-cycle in the KurreWeller-Woodruff analysis. This extra cycle does not represent a problem for the current analysis, however, which simply requires that the time period involved 
begin and end at the same point on the cycle. Portfolio variance will measure the employment instability of each economy between those two troughs regardless of the number of turning points included.

\section{RESULTS}

\section{A. Portfolio Variance and Metro Instability}

Portfolio variance values were calculated for the U.S. and for each of the seventeen MSAs over the 1975-82 business cycle. At the national level this employment cycle lasted 93 months, from March of 1975 through December of 1982. Since different endpoints were used for each MSA, some MSAs' cycles were longer than others. Columbia SC had the shortest cycle, lasting 76 months, while Ann Arbor had the longest, at 95 months. The residuals used for this analysis are from quadratic trends fitted to each industry series from January of 1972 through July of 1991 . $^{4}$

Table 1 shows that there is a wide range of portfolio variance values for this set of metro areas. The summary statistics at the bottom of the table show that the median portfolio variance is .1296 , but the values range from .0708 for Allentown to .6411 for Eugene. Figure 2 graphically presents the deviations from trend for these two extreme cases, to help give an intuitive feeling for the portfolio variance measure. This graph plots the percentage deviations of each MSA's total employment from the local trend. ${ }^{5}$ It is clear from the graph that Eugene danced more actively to the cyclical tune than sedate Allentown, consistent with Eugene's larger portfolio variance value.

Table 2 presents the portfolio variance data from Table 1, sorted from smallest to largest portfolio variance value. No clear pattern springs from this table with respect to age, type, or region of MSA. The most stable MSAs over this cycle included Allentown, Oakland and Nashville, while the most unstable included Eugene, Ann Arbor and Riverside. Eugene clearly stands out with respect to its degree of fluctuation, although Riverside and Ann Arbor also experienced instability of a major degree compared to the other fourteen MSAs. These results can be better understood by examining the components of portfolio variance.

\section{B. The Components of Portfolio Variance}

While the portfolio variance value gives important information about an MSA's degree of instability, this information could be found more simply by cal- 
TABLE 1

Portfolio Variance Results

Cycle: $1975-1982$

\begin{tabular}{|c|c|c|c|c|c|c|c|}
\hline \multirow[b]{2}{*}{ Area } & \multicolumn{2}{|c|}{ Cycle } & \multirow{2}{*}{$\begin{array}{l}\text { Portfolio } \\
\text { Variance* }\end{array}$} & \multicolumn{2}{|c|}{ Percent due to: } & \multicolumn{2}{|c|}{ Negative Covs } \\
\hline & Begin & End & & Variance & Covar & $\#$ & Weight \\
\hline U.S. & 75.04 & 82.12 & .0786 & $22.4 \%$ & $77.6 \%$ & 2 & $0.01 \%$ \\
\hline Allentown PA & 75.05 & 83.01 & .0708 & 53.3 & 46.7 & 32 & 28.27 \\
\hline Ann Arbor MI & 75.02 & 82.12 & .3820 & 60.8 & 39.2 & 20 & 3.54 \\
\hline Cincinnati $\mathrm{OH}$ & 75.05 & 83.02 & .1886 & 18.5 & 81.5 & 0 & 0.00 \\
\hline Cleveland $\mathrm{OH}$ & 75.08 & 82.12 & .1367 & 25.9 & 74.1 & 0 & 0.00 \\
\hline Columbia SC & 75.05 & 81.08 & .0965 & 49.7 & 50.3 & 30 & 20.32 \\
\hline Columbus GA & 75.02 & 82.11 & .1072 & 40.5 & 59.5 & 26 & 18.79 \\
\hline Columbus OH & 75.04 & 82.12 & .1296 & 24.7 & 75.3 & 18 & 1.73 \\
\hline Erie PA & 76.06 & 82.12 & .1753 & 31.5 & 68.5 & 12 & 0.44 \\
\hline Eugene OR & 75.01 & 82.08 & .6411 & 20.6 & 79.4 & 4 & 1.50 \\
\hline Greenville SC & 75.03 & 82.11 & .1126 & 28.7 & 71.3 & 20 & 3.04 \\
\hline Los Angeles CA & 75.03 & 82.12 & .1110 & 23.5 & 76.5 & 10 & 3.61 \\
\hline Memphis TN & 75.04 & 82.08 & .1282 & 20.7 & 79.3 & 4 & 0.86 \\
\hline Miami FL & 75.12 & 83.01 & .1449 & 25.1 & 74.9 & 24 & 15.92 \\
\hline Nashville TN & 75.03 & 82.07 & .0893 & 41.6 & 58.4 & 24 & 13.55 \\
\hline Oakland CA & 75.04 & 82.08 & .0803 & 34.4 & 65.6 & 18 & 9.18 \\
\hline Pittsburgh PA & 75.12 & 83.02 & .1444 & 30.1 & 69.9 & 2 & 0.19 \\
\hline Riverside CA & 75.03 & 82.08 & .3264 & 21.5 & 78.5 & 8 & 0.66 \\
\hline \multicolumn{8}{|c|}{ Summary statistics (excluding U.S.) } \\
\hline Mean: & & & .1803 & 32.4 & 67.6 & 14.8 & 7.15 \\
\hline Median: & 75.04 & 82.12 & .1296 & 28.7 & 71.3 & 18 & 3.04 \\
\hline Range: Min & 75.01 & 81.08 & .0708 & 18.5 & 39.2 & 0 & 0.00 \\
\hline $\operatorname{Max}$ & 76.06 & 83.02 & .6411 & 60.8 & 81.5 & 32 & 28.27 \\
\hline
\end{tabular}

*Omits two leading zeroes after the decimal point.

culating a standard measure of instability. ${ }^{6}$ Portfolio variance's real usefulness is found in examination of the components that underlie the overall measure.

\section{Industry variances}

Tables 1 and 2 also present information about the components of portfolio variance-the relative importance of industry variances, and positive and negative covariances. As explained earlier, industry variance represents the internal instability-the tendency to exhibit both "boom and bust" patterns-of an individual industry, measured without regard to the interaction of that industry with others. It measures the degree to which employment in an individual industry varies over the cycle from its own long-run trend. The ten industry variances together ac- 
FIGURE 2

Cyclical Fluctuations, Allentown and Eugene

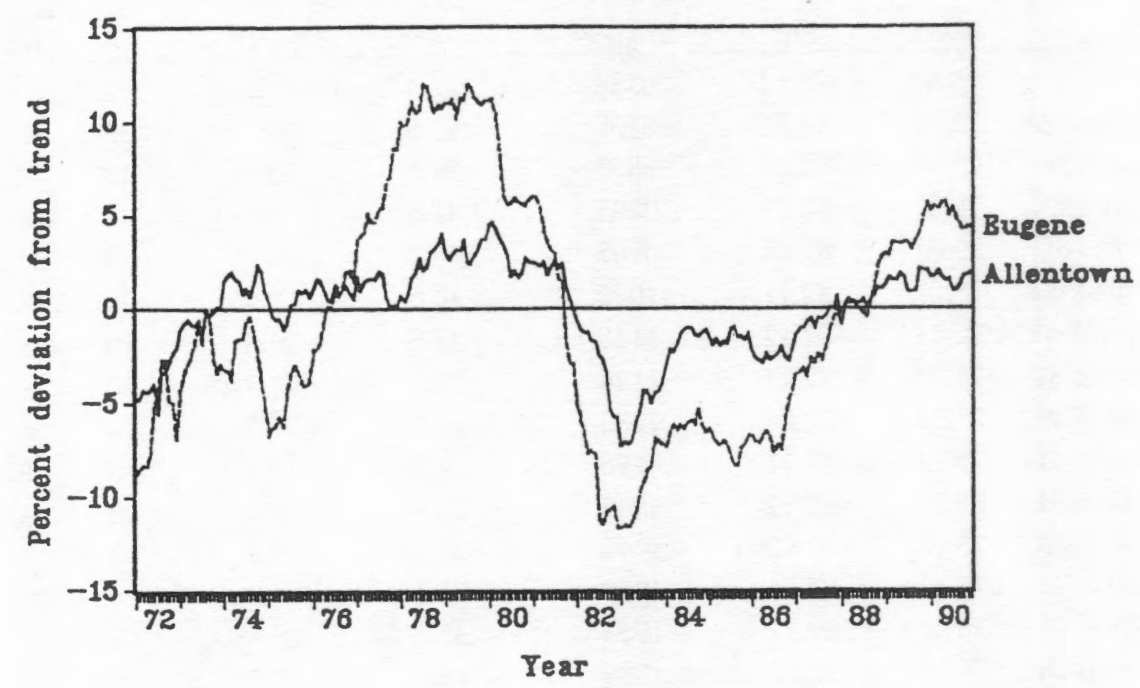

counted for 22 percent of total portfolio variance at the national level. For the seventeen MSAs, variances ranged from 19 to 61 percent of portfolio variance, but typically accounted for approximately a third.

Table 3 presents unweighted industry variances for each industry in each MSA. A quick scan of this table indicates that there are some obvious patterns in terms of industry variability. Construction is by far the most variable industry, with a mean variance of 2.65 for the sample, reflecting both its sensitivity to the business cycle and its greater seasonal variability. Construction's variance is far greater than that of durables manufacturing, which ranks second, with a variance of .708 . Services exhibit the lowest variance, .163 , followed by finance, insurance and real estate (FIR) and retailing. The same general patterns occur for the U.S. overall, at least as far as the industries at the top and bottom of the list are concerned.

As mentioned above, Table 3 presents unweighted industry variances. In calculating portfolio variance, each variance is weighted by the employment level of its industry in determining the effect on local instability. ${ }^{7}$ Table 4 presents the corresponding weighted variances, and comparison of the two tables makes it clear that consideration of the unweighted industry variances alone would present a distorted picture of the contributions of various industries to local instability. ${ }^{8}$ For example, Erie's construction industry has by far the greatest unweighted variance in that MSA, more than nine times as large as that of durables manufac- 
TABLE 2

Sorted Portfolio Variances

\begin{tabular}{|c|c|c|c|c|c|c|c|}
\hline \multirow[b]{2}{*}{ Area } & \multicolumn{2}{|c|}{ Cycle } & \multirow{2}{*}{$\begin{array}{l}\text { Portfolio } \\
\text { Variance* }\end{array}$} & \multicolumn{2}{|c|}{ Percent due to: } & \multicolumn{2}{|c|}{ Negative Covs } \\
\hline & Begin & End & & Variance & Covar & \# & Weight \\
\hline U.S. & 75.04 & 82.12 & .0786 & $22.4 \%$ & $77.6 \%$ & 2 & $.01 \%$ \\
\hline Allentown PA & 75.05 & 83.01 & .0708 & 53.3 & 46.7 & 32 & 28.27 \\
\hline Oakland CA & 75.04 & 82.08 & .0803 & 34.4 & 65.6 & 18 & 9.18 \\
\hline Nashville TN & 75.03 & 82.07 & .0893 & 41.6 & 58.4 & 24 & 13.55 \\
\hline Columbia SC & 75.05 & 81.08 & .0965 & 49.7 & 50.3 & 30 & 20.32 \\
\hline Columbus GA & 75.02 & 82.11 & .1072 & 40.5 & 59.5 & 26 & 18.79 \\
\hline Los Angeles CA & 75.03 & 82.12 & .1110 & 23.5 & 76.5 & 10 & 3.61 \\
\hline Greenville SC & 75.03 & 82.11 & .1126 & 28.7 & 71.3 & 20 & 3.04 \\
\hline Memphis TN & 75.04 & 82.08 & .1282 & 20.7 & 79.3 & 4 & 0.86 \\
\hline Columbus $\mathrm{OH}$ & 75.04 & 82.12 & .1296 & 24.7 & 75.3 & 18 & 1.73 \\
\hline Cleveland $\mathrm{OH}$ & 75.08 & 82.12 & .1367 & 25.9 & 74.1 & 0 & 0.00 \\
\hline Pittsburgh PA & 75.12 & 83.02 & .1444 & 30.1 & 69.9 & 2 & 0.19 \\
\hline Miami FL & 75.12 & 83.01 & .1449 & 25.1 & 74.9 & 24 & 15.92 \\
\hline Erie PA & 76.06 & 82.12 & .1753 & 31.5 & 68.5 & 12 & .44 \\
\hline Cincinnati $\mathrm{OH}$ & 75.05 & 83.02 & .1886 & 18.5 & 81.5 & 0 & 0.00 \\
\hline Riverside CA & 75.03 & 82.08 & .3264 & 21.5 & 78.5 & 8 & 0.66 \\
\hline Ann Arbor MI & 75.02 & 82.12 & .3820 & 60.8 & 39.2 & 20 & 3.54 \\
\hline Eugene OR & 75.01 & 82.08 & .6411 & 20.6 & 79.4 & 4 & 1.50 \\
\hline
\end{tabular}

*Omits two leading zeroes after the decimal point.

turing. However, construction is one of the smaller industries in Erie, accounting for only three percent of total employment. As a result, construction's fluctuations have a smaller impact on overall instability than durables manufacturing, which has a very large share of employment. (This issue of weights vs. fluctuations will arise again later in the paper.)

In terms of weighted variances, durables manufacturing ranks at the top of the list for this sample of MSAs. State and local government takes second place, followed by retailing and services. Notice that both retailing and services ranked near the bottom in the unweighted variances, but both rank near the top in terms of weighted variances. This is due to the fact that in terms of employment both industries are among the largest in all MSAs in the sample.

\section{Covariances, positive and negative}

The examination of local instability patterns turns naturally to an examination of industry variances, as discussed above. Even the most casual observer would realize that it is necessary to look at fluctuations in individual industries in order to understand fluctuations in total employment. However, research that con- 

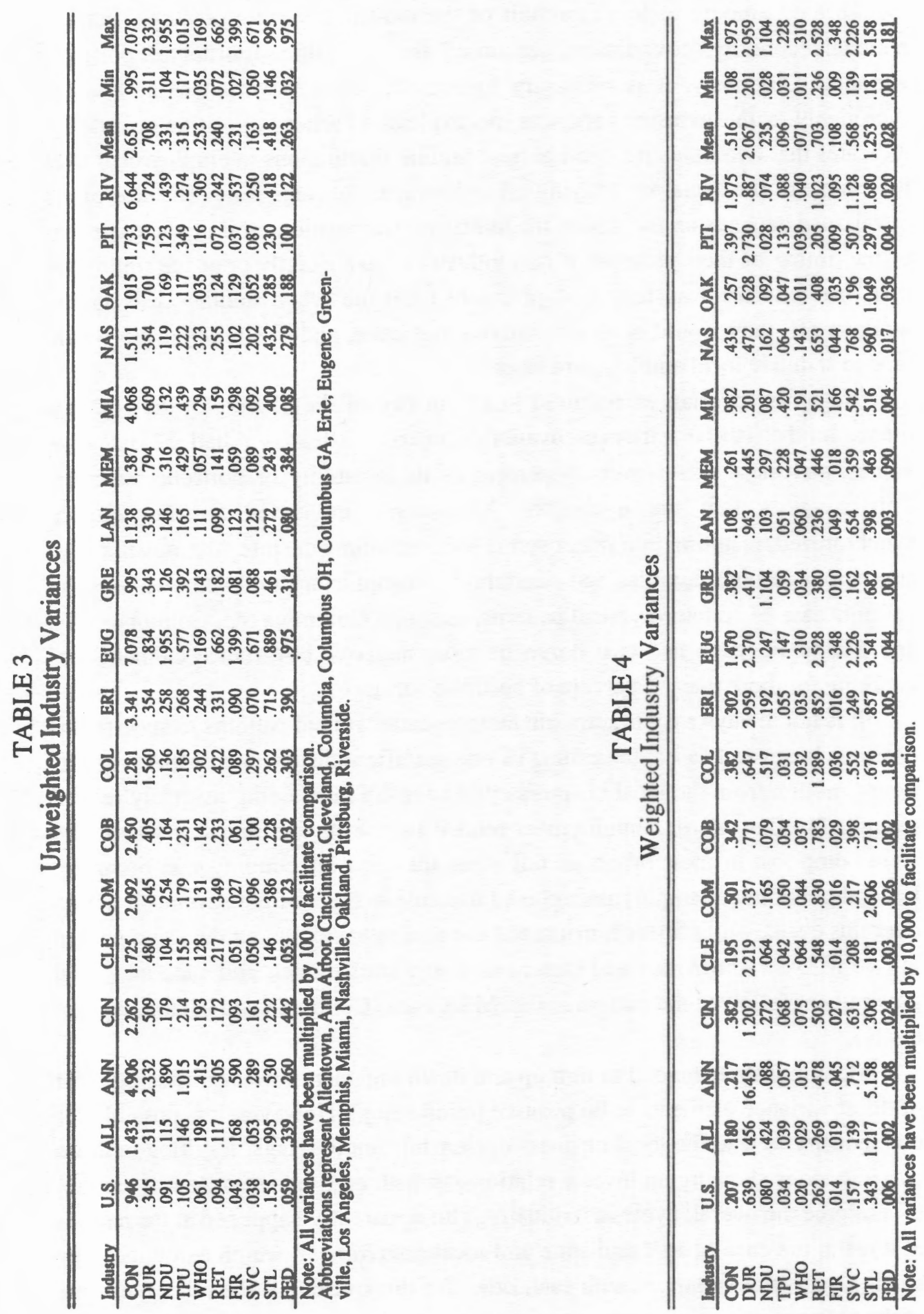
siders only these effects would miss most of the story. Covariances typically accounted for approximately two-thirds of total portfolio variance in this sample, although they amount to less than half of the total in a couple of cases. For the national economy, covariances accounted for over three-fourths of portfolio variance. Obviously, it is necessary to consider these covariances at least as thoroughly as the industry variances. As explained earlier, a positive covariance indicates that two industries tend to have similar fluctuations in employment over the course of the cycle, both laying off or hiring at the same time. The size of the covariance depends on the size of the industries' fluctuations and on the closeness of the timing of their patterns. If two industries have exactly opposite timing, so that one industry was hiring at precisely the time when another was laying workers off, they would have a negative covariance, and this relationship would tend to stabilize local employment levels.

Negative covariances occurred in all but two of the MSAs. Of the 100 elements in the 10x10 variance-covariance matrix, Allentown had 32 negative values, and these offset over 28 percent of its instability or portfolio variance. This suggests that the cycles of Allentown's industries are not closely synchronized, resulting in a rather stable local economy despite Allentown's concentrations in both durables and nondurables manufacturing. Allentown was the extreme case of counter-cyclical patterns, although Columbia SC, Columbus GA, and Miami FL each had two dozen or more negative covariance elements accounting for more than 15 percent of portfolio variance.

It is not always easy to attribute these countercyclical patterns to specific industries. In several cases, the timing of one specific industry in an MSA was different enough from the local business cycle to result in its being inversely related overall. In other words, employment tended to rise in this industry when jobs were being lost in most others or fall when the general economy was booming. Federal government employment played that role in eight of the seventeen MSAs over this cycle, while finance, insurance and real estate exhibited the same pattern in two MSAs (Ann Arbor and Greenville), and construction and state and local government followed the pattern in one MSA each (Columbia and Miami, respectively).

Most industries tended to turn up and down together, however, causing most of the covariance elements to be positive (reinforcing). However, it is possible for one industry to lead the local business cycle while another lags, resulting in those two industries showing an inverse relationship with each other while still tending to reinforce the overall cycle individually. This apparently happened at the national level in the case of FIR and state and local government, which exhibited very small negative covariances with each other for this cycle. All the other elements of the U.S. variance-covariance matrix were positive. 


\section{Industry Contributions to Portfolio Variance}

This leads us to consider the effect of individual industries on local employment instability. Obviously, some industries contribute more to local fluctuations than others. The contribution of individual industries to local fluctuations can be measured by summing the weighted variance and the nine covariance elements for each industry. Table 5 presents this information for the seventeen MSAs and for the U.S. overall. (The column for each area sums to 100 percent, except for rounding.)

Consider the column for the Erie MSA, as an example. The durables manufacturing industry is the one that contributes most to Erie's instability, accounting for over 36 percent of local portfolio variance. The retailing industry ranks a distant second with not quite 19 percent, followed by state and local government, with 14 percent. These three industries together account for nearly 70 percent of local employment instability, both through their own fluctuations (variances) and due to the fact that they tend to be rising and falling at the same time as other industries locally (covariances).

This table also shows that federal government employment tends to be countercyclical overall in Erie, as evidenced by the negative value of its contribution. The effect is quite small, however, accounting for only about one-eighth of one percent of total portfolio variance. Examination of the U.S. data in this table show that Erie's experiences are similar to those of the nation overall. Durables manufacturing also contributed the most to instability at the national level, but it only accounted for 27 percent of the total there. Retailing was also second nationally with 14 percent, but construction ranked third with 13 percent, followed by services, with 11 percent. While the federal government was the industry that contributed least to national portfolio variance, it did contribute a positive amount and was not countercyclical as in the Erie economy.

A quick scan of Table 5 shows that there are some general patterns, although there is also significant variation from area to area. Durables manufacturing ranked first or second in contribution to instability in twelve of the seventeen MSAs, followed closely by retailing. On the other extreme, the federal government ranked at the bottom of the list or second from the bottom in all seventeen cases. The last three columns of Table 5 present summary statistics which reinforce this impression. On average, durables manufacturing accounted for 25 percent of portfolio variance in this sample, close to the 27 percent of the national economy. Retailing accounted for 17 percent, followed by services with 13 percent, and state and local government with 12 percent. Federal government accounted for only 0.14 percent, however, followed by FIR with less than 3 percent, and wholesale trade with not quite 5 percent. 

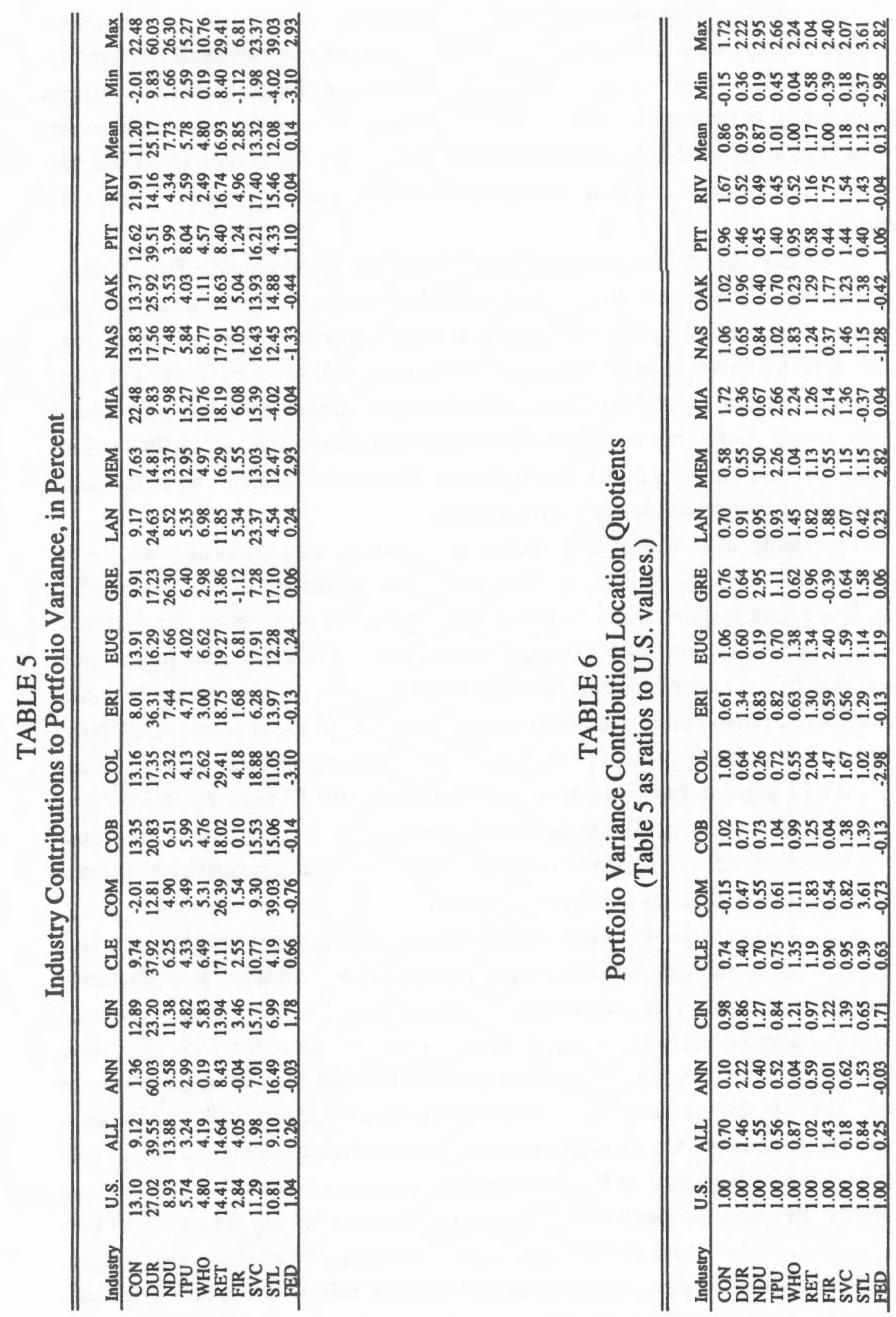
However, there are some significant deviations from the general patterns. Table 5 shows that durables' contribution varied from less than 10 percent of portfolio variance in Miami to over 60 percent in Ann Arbor. While construction contributed an average of 11 percent to portfolio variance in this sample, it was countercyclical in Columbia SC, actually helping to stabilize the economy there over this cycle. State and local government is another sector with widely varying effects; in several MSAs it ranked near the top in contributing to instability, but in Los Angeles it was one of the most stable industries, and in Miami it was countercyclical. Such variation may be due to different political structures in the case of state and local government, but is less explainable for other industries.

\section{Industry Size versus Cyclical Behavior: Industry Instability Location Quotients}

So why do industries vary so much across MSAs in their impact on local instability? One way to approach this question is to ask how much of an industry's effect is due to its size, and how much is due to its own cyclical patterns. Obviously, an industry that is very large locally will have a much greater impact on the local economy than one that is Lilliputian. To some extent, the small effect that federal government employment typically had on local instability may be due to the fact that it is the smallest of the ten industries considered in this study. On the other hand, services, retailing, and state and local government are all larger than durables manufacturing, yet durables tends to have a larger effect than any of those.

In order to disentangle these effects, let us examine instability patterns and employment patterns in the MSAs relative to the nation. Table 6 presents the contributions of each industry to portfolio variance-the same data in Table 5-but compares it to the national numbers in the first column of Table 5. For example, the 1.34 value for Erie durables in Table 6 means that the 36.31 percent contribution of Erie's durables industry was 1.34 times as large as the 27.02 percent durables contribution to U.S. portfolio variance.

The numbers in Table 6 could be considered location quotients for each industry's contribution to portfolio variance; a value equal to one indicates a situation in which an industry in an MSA makes exactly the same contribution to local portfolio variance as the national industry does to U.S. portfolio variance. In other words, its pattern in this MSA matches its pattern nationally. Values significantly different from one identify cases in which something unusual is going on at the local level.

Differences from the national pattern may be due to the local industry's (1) being exceptionally large or small locally or (2) having different cyclical 
timing patterns or amplitudes. We can distinguish the size effect by looking at the industrial breakdown of each area's economy. Table 7 presents this information. To make comparisons easier, Table 8 converts these values into standard employment location quotients. Erie's 2.12 location quotient for durables means that Erie's 28.91 percent of employment in durables manufacturing was 2.12 times as great as the 13.61 percent employed in that industry nationally.

We can discover the amount of an industry's instability contribution that is due to different cyclical timing and amplitude by comparing its portfolio variance contribution location quotient in Table 6 with its employment location quotient in Table 8. For example, consider the service industry in Los Angeles. Table 5 shows that this industry contributed 23.4 percent to L.A.'s portfolio variance, far more than the 11.3 percent that services contributed to national portfolio variance. This is partially due to the fact that the services industry makes up a bigger share of local employment-22.9 percent in L.A. versus 20.5 percent nationally, as seen in Table 7. However, the difference in portfolio variance contributions (23.4 vs. 11.3 ) is much greater than the difference in employment shares (22.9 vs. 20.5). This implies that the Los Angeles services industry is contributing instability above and beyond the fact that it accounts for a larger-than-average amount of the area's employment. In other words, the service industry's cyclical patterns are more severe in L.A. than in the same industry elsewhere, even after accounting for the size of the industry in L.A.

One way to measure this effect would be to calculate the ratio of the portfolio variance contribution location quotients in Table 6 to the employment location quotients in Table 8. Table 9 presents these ratios, which we might call industry instability location quotients (IILQ):

$$
\mathrm{ILQ}_{\mathrm{ij}}=\left(\mathrm{CPV}_{\mathrm{ij}} / \mathrm{CPV}_{\mathrm{iUS}}\right) /\left(\mathrm{E}_{\mathrm{ij}} / \mathrm{E}_{\mathrm{iUS}}\right)
$$

where: $\begin{array}{ll}\mathrm{CPV}_{\mathrm{ij}} & =\begin{array}{l}\text { percentage contribution of industry } \mathrm{i} \text { to region } \mathrm{j} \text { 's } \\ \text { portfolio variance, }\end{array} \\ \mathrm{CPV}_{\mathrm{iUS}} & =\begin{array}{l}\text { percentage contribution of industry } \mathrm{i} \text { to the nation's } \\ \text { portfolio variance, }\end{array} \\ \mathrm{E}_{\mathrm{ij}} & =\begin{array}{l}\text { industry i's percent of region } \mathrm{j} \text { 's total employment, } \\ \text { and }\end{array} \\ \mathrm{E}_{\mathrm{iUS}} & =\text { industry i's percent of total national employment. }\end{array}$

The top of the fraction is the "contribution to portfolio variance" location quotient and the bottom of the fraction is the standard employment location quotient.

The IILQ has the virtue of allowing us to do a quick comparison of an industry's instability patterns in each MSA with its pattern at the national level. A 

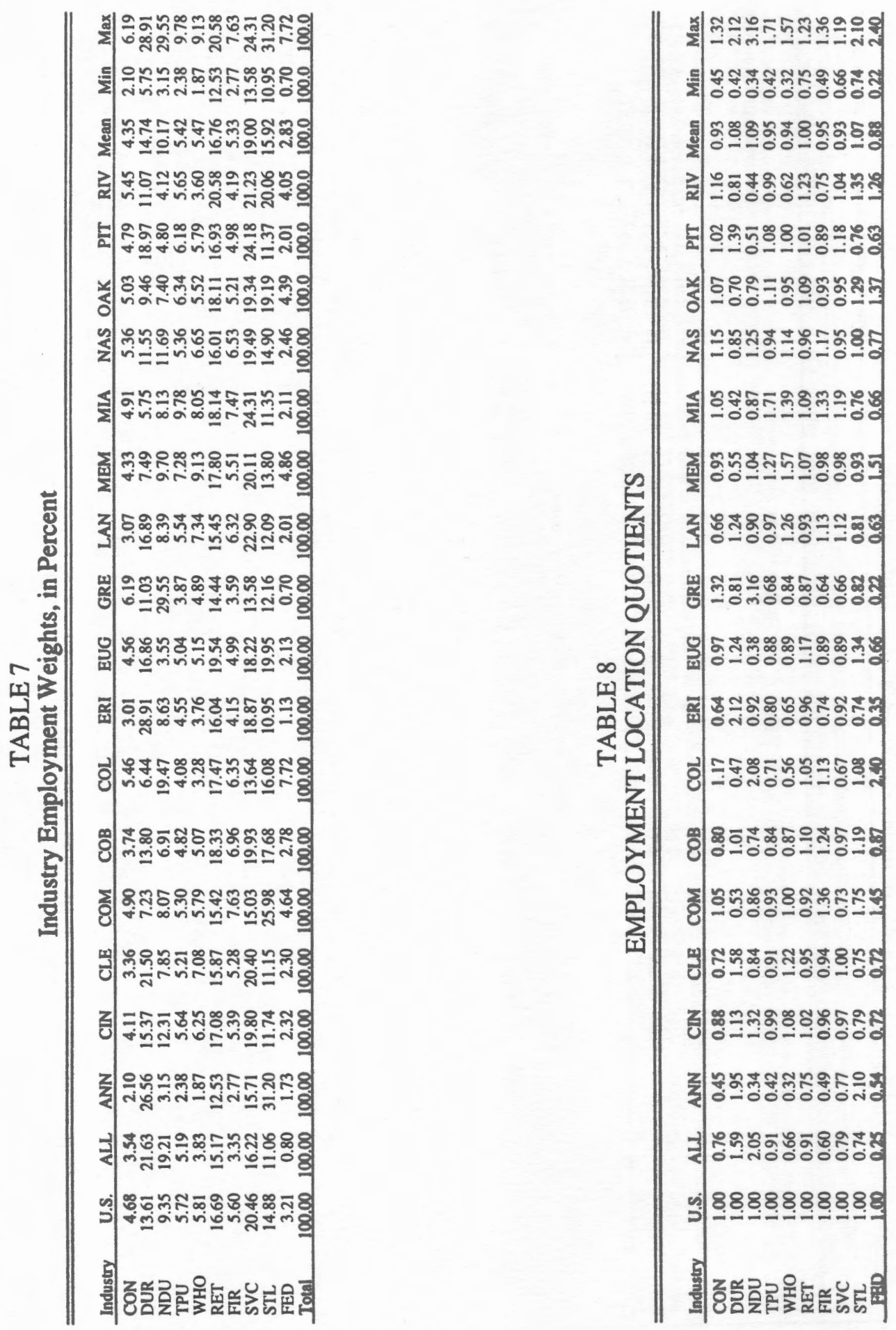


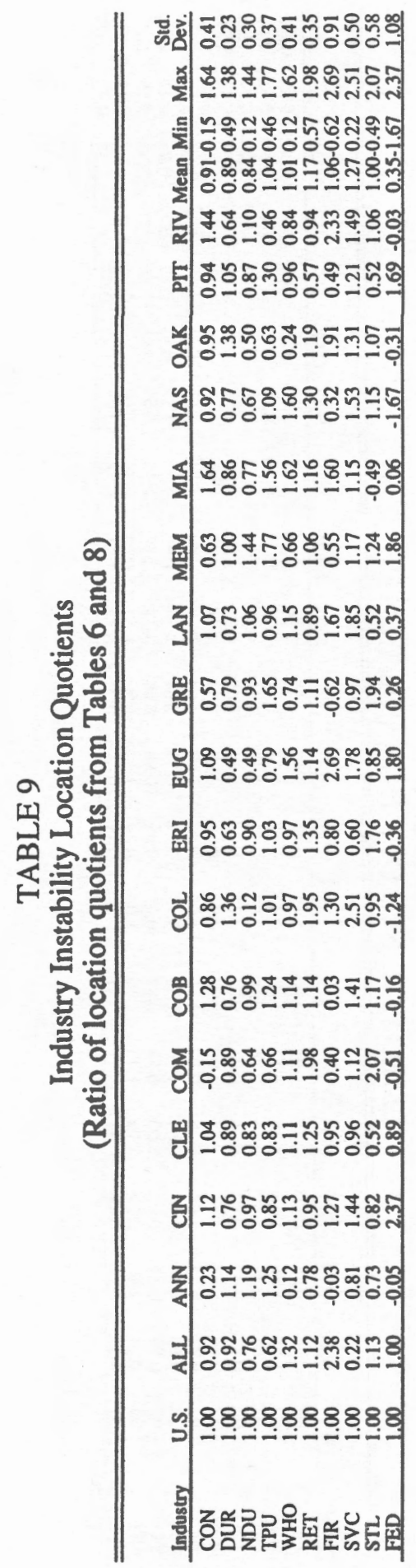


value of one would mean that the local industry is just as stable or unstable as the industry is in the nation overall, in relative terms. A value of two would mean that it contributes twice as much to instability locally as it does at the national level, even after adjusting for the relative size of the industry in the two economies. Consistency across MSAs would result in all IILQs taking a value of one.

The 1.00 value in Table 9 for the federal government IILQ in Allentown results from the fact that this industry's small contribution to portfolio variance (only 25 percent of the amount typical for this industry nationally) is completely due to the fact that this industry is much smaller in Allentown than elsewhere (only 25 percent of the federal government's employment share nationally.) On the other hand, Cleveland's IILQ of 0.52 for state and local government indicates that this industry is relatively more stable there, since in Cleveland it accounts for only about 39 percent of the typical contribution of that industry nationally (4.19 percent vs. 10.81 percent), but 75 percent of the typical employment share (11.15 percent vs. 14.88 percent).

Descriptive statistics for the industry instability location quotients for this sample of seventeen MSAs are presented in the last four columns of Table 9. The standard deviations are the key piece of information here. They indicate the degree to which an industry exhibited consistent patterns across the seventeen MSAs during the period. A zero standard deviation would indicate that the industry displayed the exact same ILQ in all of the MSAs. The small standard deviation for durables manufacturing means that this industry displayed relatively consistent behavior across the sample MSAs-it contributed to instability anywhere from 49 percent to 138 percent of the amount that would be expected from its size. Federal government employment, on the other hand, had the highest standard deviation (1.08), reflecting the fact that its behavior varied significantly from one MSA to the next. It sometimes contributed much more and sometimes much less than its size would lead us to expect. In the extreme cases, federal government in Cincinnati contributed 2.37 times as much to instability as would have been expected from its size, while in Nashville it actually reduced instability, with a ratio of -1.67 .

It may be argued that the summary statistics for the IILQs in Table 9 tell more about the characteristics of the sample MSAs than about the industries themselves. However, if these MSAs are representative of the larger set of MSAs, the results would indicate that some industries (such as durables and nondurables manufacturing) tend to have more consistent patterns across metro economies than others. The issue of consistency of industrial patterns across metro areas may turn out to be a crucial one for portfolio variance. In order for the technique to be useful in a prescriptive way, it must be possible to predict the effect that attraction of a given industry would have on a local economy. If each industry interacts with 
each MSA's existing industries in a totally unpredictable way, this would be impossible. Data presented in this paper indicate that the problem is not so severe as to warrant scrapping of the technique, but it does bear further examination.

\section{CONCLUSIONS}

From our examination of ten industries across seventeen MSAs and the United States overall during the 1975-82 business cycle, we draw the following conclusions:

- Portfolio variance (and its evil twin, instability) varies significantly across MSAs.

- Covariances play a more important role in determining portfolio variance than do individual industry variances.

- Negative covariances are of varying degrees of importance in different MSAs. Some MSAs exhibited no countercyclical industry relationships at all, while negative covariances accounted for (offset) more than a quarter of total portfolio variance in other MSAs.

We clearly found some general patterns among individual industries with regard to instability:

- In terms of unweighted industry variances, construction showed a significant degree of instability, unsurprisingly, followed by durables manufacturing. The services, federal government, and finance, insurance, and real estate industries were most stable.

- Considering the weighted variances and covariances, the durables manufacturing industry was a prime contributor to instability in most of the MSAs examined. State and local government, retailing and services often contributed a significant amount, also.

In this paper, we have devised a technique for separating the size effect from the cyclical behavior of industries, and results of this analysis suggest that all industries exhibited some variation in pattern across MSAs. Some, like federal government, showed quite different patterns in different MSAs. This industry was significantly more variable in some MSAs than others, and in fact was countercyclical in eight of the seventeen. State and local government showed a similar pattern of variation across MSAs. Durables manufacturing, on the other hand, exhibited a rather small range of variation from MSA to MSA; it always tended to exhibit the same pattern of instability.

Aside from suggesting a new tool for measuring an industry's contribution to local instability, a key conclusion of this paper is that there are some clear general patterns in terms of individual industries' effects on metro instability, but there is 
also a wide degree of variation from those patterns in individual cases. This does not necessarily mean that industrial targeting for purposes of local stabilization is impossible, however. It simply means that those who seek to do so must be a little more sophisticated in their analysis. In fact, Schoening and Sweeney (1992) offer an approach to deal with this difficulty, which involves using "neighborhood" economies to gauge the likely effect of a potential target industry. The findings in our research indicate that the use of an approach like Schoening and Sweeney's is entirely appropriate.

We should also point out that this paper has attempted to examine the issue of metropolitan instability from but a single perspective-that of industrial structure. In this, it uses but a single tool-portfolio variance. There are certainly other factors that will play a role in such a complex topic, but these remain for other research projects.

\section{ENDNOTES}

1. There have been many studies that examine the relationship between regional economic instability and various measures of industrial diversification. In one such study, Sherwood-Call (1990) states that ". . economic diversification should reduce only the amount of regional economic volatility that is diversifiable, or nonsystematic" (p. 18, her emphasis.) However, she defines diversification using the national average (coefficient of specialization) approach, so it may be appropriate for her to say that some amount of instability-that associated with the national economy-cannot be avoided. With portfolio variance, however, this need not be the case. A regional economy could, theoretically, be perfectly stable regardless of fluctuations in the national economy if it has the correct balance of positive and negative covariance industries. This exposes one of the drawbacks of the national average or coefficient of specialization approach to measuring diversification; by definition, it does not allow a regional economy to be more diversified than the national economy.

2. The six MSAs are Ann Arbor, Columbia, Erie, Greenville, Memphis and Nashville.

3. Official NBER turning points for the overall economy are listed in "Business Cycle Expansions and Contractions" Survey of Current Business, v. 71, \#4, (April 1991), p. C-25. Turning points for total employment are listed in "Specific Peak and Trough Dates for Selected Indicators" on page C-26 of that issue.

4. January of 1972 through December of 1990 for the U.S. series.

5. For this graph, the percentage deviation series have been seasonally adjusted to allow the cyclical fluctuations to be seen more clearly. The actual 
portfolio variance values also reflect differences in seasonal fluctuations from area to area, as explained in an earlier section.

6. For a good measure of instability, Conroy $(1972,1975)$ suggests using relative standard deviation-standard deviation of total employment from trend value, expressed as a percentage of mean employment level within the cycle. Since variation in total employment is equal to the sum of variation in each industry, this instability measure will be identically equal to portfolio variance, as suggested in Kurre and Weller (1984).

7. As explained earlier, the variances are actually weighted by the employment level squared.

8. Notice that the variances in Table 3 have been multiplied by 100 to facilitate comparison, while those in Table 4 have been multiplied by 10,000 (i.e., $100^{2}$.) This means that direct comparison of the numbers in Table 3 and Table 4 is not appropriate. Rather, the comparison should consider the industry rankings in each table and the variance values relative to others in the same table.

\section{REFERENCES}

Board, John, and Charles Sutcliffe. "Risk and Income Tradeoffs in Regional Policy: A Portfolio Theoretic Approach." Journal of Regional Science 31 (1991): 191-210.

Brown, Deborah J., and Jim Pheasant. "A Sharpe Portfolio Approach to Regional Economic Analysis." Journal of Regional Science 25 (1985): 51-63.

"Business Cycle Expansions and Contractions." Survey of Current Business 71, \#4 (1991): C-25.

Conroy, Michael E. "Optimal Regional Industrial Diversification: A PortfolioAnalytic Approach." Unpublished Ph.D. dissertation, The University of Illinois at Urbana-Champaign (1972).

"The Concept and Measurement of Regional Industrial Diversification." Southern Economic Journal 41 (1975): 492-505.

Coulson, N. Edward. "The Sources of Sectoral Fluctuations in Metropolitan Areas." Journal of Urban Economics 33 (1993): 76-94.

Jackson, Randall W. "An Evaluation of Alternative Measures of Regional Industrial Diversification." Regional Studies 18 (1984): 103-112.

Kort, John R. "A Perspective on the Economic Diversity/nnstability Literature: Are We Really Providing New Directions and Policy Prescriptions?" Paper presented at the 38th North American Meetings of the Regional Science Association International, New Orleans, LA. November 1991.

Kurre, James A., and Barry R. Weller. "Use of the Industrial Portfolio Approach in Time-Series Analysis of the Regional Business Cycle." Paper presented at 
the Northeast Business and Economic Association Annual Conference, Boston, MA. 1984.

"Regional Cyclical Instability: An Empirical Examination of Wages, Hours and Employment Adjustments, and an Application of the Portfolio Variance Technique." Regional Studies 23 (1989): 315-329.

Kurre, James A., Barry R. Weller, and Clifford H Woodruff. "The Timing of Metropolitan Business Cycles." Paper presented at the 38th North American Meetings of the Regional Science Association International, New Orleans, LA. November, 1991.

Kurre, James A., and Clifford H. Woodruff. "Sensitivity of the Portfolio Variance Technique to Data Frequency and Type." Paper presented at the 29th Annual Meetings of the Southern Regional Science Association, Washington, DC. 1990a.

"Sensitivity of the Portfolio Variance Technique to Level of Industrial Detail and Real vs. Nominal Data." Paper presented at the 37th North American Meetings of the Regional Science Association International, Boston, MA. November, $1990 \mathrm{~b}$.

Malizia, Emil E. and Shanzi Ke. "The Influence of Economic Diversity on Unemployment and Stability." Journal of Regional Science 33 (1993): 221-235.

Schoening, Niles C. and Larry E. Sweeney. "Applying an Industrial Diversification Decision Model to Small Regions." Review of Regional Studies 19 (1989): 14-17.

. "Proactive Industrial Development Strategies and Portfolio Analysis." Review of Regional Studies 22 (1992): 227-238.

Sherwood-Call, Carolyn. "Assessing Regional Economic Stability: A Portfolio Approach." Economic Review (Federal Reserve Bank of San Francisco) Winter, 1990: 17-26.

"Specific Peak and Trough Dates for Selected Indicators." Survey of Current Business 71, \#4, (1991): C-26.

U.S. Department of Labor, Bureau of Labor Statistics. BLS Handbook of Methods. Bulletin 2285. Washington, D.C.: U.S. Government Printing Office, April 1988.

Employment, Hours and Earnings, States and Areas, 1972-87. Volumes I-V. Bulletin 2320. Washington, D.C.: U.S. Government Printing Office, March 1989.

. Employment, Hours and Earnings, United States, 1909-90. Volumes III. Bulletin 2370. Washington, D.C.: U.S. Government Printing Office, March 1991.

Weller, Barry R., and James A. Kurre. "Measuring Regional Instability: Industry Weight Sensitivity of the Portfolio Variance Technique." Paper presented at 
the 11th Annual Convention of the Eastern Economic Association, Pittsburgh, PA. 1985.

White, Sammis B., John F. Zipp, William F. McMahon, Peter D. Reynolds, Jeffrey D. Osterman and Lisa S. Binkley. "ES202: The Data Base for Local Employment Analysis." Economic Development Quarterly 4 (1990): 240253. 